Check for updates

Cite this: RSC Adv., 2019, 9, 32911

Received 11th June 2019

Accepted 12th September 2019

DOI: 10.1039/c9ra04391h

rsc.li/rsc-advances

\section{Influence of different dispersants on rheological behaviors of coal water slurry prepared from a low quality coal}

\author{
Shunxuan Hu, (D) ab Liming Liu, ${ }^{\text {ab }}$ Xin Yang, ${ }^{c}$ Junguo Li, ${ }^{d}$ Baonan Zhou, ${ }^{\text {ab }}$ \\ Changning $\mathrm{Wu}^{\star}{ }^{\star d} \mathrm{Li}_{\mathrm{W}} \mathrm{Weng}^{\mathrm{bd}}$ and Ke Liu${ }^{\star b d}$
}

To improve the efficiency of the gasification or combustion process of coal water slurry (CWS), it is significant to optimize the rheological properties and increase the solid concentration of CWS. Particularly, preparing CWS from low quality coal remains a peculiarly intriguing subject due to the large reserve and low price of low quality coals in China and very successful industrial applications of CWS all over the world. In this work, refined coal particles were obtained by applying an improved fine particle flotation method on a low quality coal. The refined coal used for CWS preparation had a much lower ash content and higher calorific value than those of the raw coal, which could hardly be utilized for preparing a qualified CWS in basic fluidity. The CWS derived from the refined coal had a good fluidity, with apparent viscosity of $1045.75 \mathrm{mPa}$ s and solid concentration >60 wt\% in dispersant free conditions. The effects of dispersants i.e., Naphthalene Sulfonate Formaldehyde condensate (NSF), Polyoxyethylene Polycarboxylic Acid ether (PPA), and Sulfonated Melamine-Formaldehyde resin (SMF), and their dosages on the rheological characteristics of CWS prepared with the refined coal had been investigated. Experimental results showed that slurry ability for CWS was obviously improved by using the refined coal. This was due to the decrease in both the porosity and hydrophilicity of coal particles as confirmed by SEM and FT-IR analyses. The apparent viscosity of CWS was decreased by $30 \%-60 \%$ by adding one of those dispersants with a dosage of $0.6 \mathrm{wt} \%$. Through observation of the rheological behaviors, the CWS samples generally behaved as a shear thinning fluid, and the measured viscosity was well correlated by the Herschel-Bulkley equation. The PPA dispersant exhibited the best performance on reducing the viscosity and yield stress among the dispersants in this study. It could be attributed to the best improvement in wettability of the coal surface and the largest decrease in surface tension of deionized water by PPA. The electrostatic force might have little contribution to viscosity reduction of CWS in this suspension.

\section{Introduction}

Coal is the major energy source due to its abundant reserves and relatively low price in China. The Chinese government has paid much attention to the development of advanced clean coal technologies to reduce the emissions $\left(\mathrm{NO}_{x}, \mathrm{SO}_{2}\right.$, fine particles, etc.) from coal utilization and improve the energy efficiency. ${ }^{1,2}$ CWS was generally regarded as one of the promising technologies for the clean utilization of coal because of its advantages

\footnotetext{
${ }^{a}$ School of Chemistry and Chemical Engineering, Harbin Institute of Technology, Harbin 150001, China

${ }^{b}$ Department of Chemistry, Southern University of Science and Technology, Shenzhen 518055, China

'Department of Engineering Science, University of Oxford, Oxford, OX2 OES, UK ${ }^{d}$ Clean Energy Institute, Academy for Advanced Interdisciplinary Studies, Southern University of Science and Technology, Shenzhen 518055, China. E-mail: wucn@ sustech.edu.cn; liuk@sustech.edu.cn
}

in being a potential cost-efficient alternative to oil and decreasing $\mathrm{SO}_{2}$ and $\mathrm{NO}_{x}$ emissions compared to the conventional coal combustion. ${ }^{3,4}$ A desirable CWS should maintain (i) a high coal percentage to increase the heating value and (ii) a low apparent viscosity for liquid fuel transportation through the pipelines. ${ }^{5,6}$ Therefore, it was significant to study the rheological properties of the CWS, which are generally influenced by the coal properties (including the coal rank, coal porosity, particle size, mineral composition, etc.), ${ }^{7,8}$ preparation technology (including picking, crushing, grinding, mixing and shearing), ${ }^{9}$ and the additives. ${ }^{10,11}$

It was learned that increasing the coal rank can improve the slurry ability of coal and this could be relevant to the lower O/C ratio in the higher coal rank..$^{12}$ Also, some studies found that lower ash content could increase the viscosity of CWS. ${ }^{13,14}$ Considering the relatively high price of higher rank coals (bituminous/anthracite), the relatively cheaper low quality coal with an adequate reserve could be attractive for preparing CWS 
in China. However, the high mineral content and abundant pores of low quality coals make it difficult to prepare the qualified CWS directly. In order to prepare high quality CWS from low quality coal, it was necessary to study the methods on upgrading the low quality coal especially from the aspects of coal de-ashing and particle surface modification.

There were a variety of methods on coal de-ashing, mainly included the chemical techniques (such as strong acid/base treatments, etc.), ${ }^{\mathbf{1 5}}$ physical techniques (such as ultrasonic, gravity, magnetic and electrostatic separation method, etc.) and physico-chemical techniques (such as oil agglomeration, selective flocculation flotation (SFF), triboelectric separation, etc.). ${ }^{16,17}$ In addition, the physico-chemical methods could be more effective in separating the inorganic components than the physical methods, in particular for fine particles, while the chemical methods had the disadvantages in the environment protection and the relatively higher cost. The SFF method had attracted much attention among these physico-chemical deashing methods because of its high efficiency for processing high ash and difficult-to-float fine coal particles. ${ }^{18,19}$ Selective adsorption of collecting agent onto the coal particle surface made flocculation of hydrophobic components feasible while refusing hydrophilic particles (mainly mineral substance). The selectivity of aggregation and variation in particle size improved the purification of coal. ${ }^{20}$ Therefore, this method had been chosen to be the de-ashing and surface modification means in this study. To the best of our knowledge, there had been little study on using the refined coal obtained from the SFF method for CWS preparation.

In CWS preparation processes, dispersants could be employed to reduce the apparent viscosity of CWS by modifying the coal surface. ${ }^{21,22}$ According to the charge properties of molecular chains, CWS dispersants included nonionic, anionic and cationic classes. Because of high cost and poor dispersion effect, cationic dispersants were rarely used in industry. The influence of dispersants on the surface properties of coal included two aspects: (1) dispersants could reduce the surface hydrophobicity of coal particles, for reducing the interface stress difference between particles and solution, so that the particles were homogeneously dispersed in the slurry; (2) dispersants could enhance the electronegativity of coal particle to improve electrostatic repulsion between particles, thereby reducing the agglomeration of particles in the slurry. ${ }^{23,24}$ The dosage of dispersant accounted for $0-1 \mathrm{wt} \%$ of coal powder on a dry basis. ${ }^{9,25}$ If the amount of dispersant was too small, the particles could not be adequately modified; but if the addition of dispersant was too much, the slurry viscosity was increased when excess of the dispersing agent entered into solvent. ${ }^{9}$ Hence, it was significant to investigate how different types of dispersants and their dosage can affect the surface properties of the refined coal for CWS preparation.

Therefore, this study aimed to experimentally investigate (i) the apparent viscosity of CWS prepared by the refined coal obtained from a low quality coal slime by using the improved SFF method proposed in this study and (ii) the effect of different dispersants on adjusting the rheological behavior of the CWS. The morphology and surface functional group differences of the original coal and the refined coal were investigated primarily. Then, the apparent viscosity of CWS prepared by the original coal and the refined coal with different solid content was proposed, meanwhile the correlation between the apparent viscosity of CWS and the surface properties of coal particles was discussed. Finally, the effects of different dispersants on reducing apparent viscosity and improving rheological behavior of CWS prepared by refined coal were studied, simultaneously the contact angle, surface tension and zeta potential experiments were used to understand the associative strength of different dispersants.

\section{Experiments}

\subsection{Materials}

2.1.1. Preparation of refined coal. The Jinda refined coal (denoted as JD-RC), which was used for CWS preparation in this experimental study, was obtained from the dried Jinda coal slime (denoted as JD-CS) by the improved SFF method developed in our group. In order to strengthen the adsorption of collectors, a pre-mineralization unit was introduced before separation, and this improved SFF method significantly improves the recovery of combustible and the quality of refined coals. The flow chart of improved SFF method for refined coal production was shown in Fig. 1.

The whole process were as follows: firstly JD-CS was crushed and milled into fine particles with $d_{90}$ less than $100 \mu \mathrm{m}$, for gaining a higher dissociation rate between organic rocks and minerals, because most of minerals were embedded in coal with particle size of 1-50 $\mu \mathrm{m} .{ }^{26}$ Then the surface of fine coal particles was selectively modified by $0.4 \mathrm{wt} \%$ of $\mathrm{C} 11-\mathrm{C} 17$ alkanes (to enhance the surface hydrophobic effect of particles) and micronano bubble (to enhance the buoyancy of particles), which could promote the formation of refined coal agglomerates at $10000 \mathrm{rpm}$ high speed shear for $3 \mathrm{~min}$ in a pre-mineralization equipment. ${ }^{27}$ Finally, these modified coal particles were fed into a flotation tower with a height of $2 \mathrm{~m}$ and a diameter of $200 \mathrm{~cm}$ for separation, and the refined coal with low ash content were collected as raw material for CWS preparation.

2.1.2. Coal properties. Experiments were mainly conducted with slurries of JD-CS and JD-RC in the deionized water. The coal particle size was measured by a laser particle size analyzer (LS-13-320 by Beckman Co., America).

The particle size distribution of JD-CS and JD-RC, which was used for all experiments involving slurry preparation, characterization and measurements, was shown in Fig. 2. Proximate, ultimate and calorific value analyses of JD-CS and JD-RC were given in Table 1.

\subsection{Preparation of CWS}

A specified amount of JD-RC (based on the solid content in the targeted slurry) was added to a weighed amount of deionized water. For experiments involving dispersants, the required amount of additive was firstly added to deionized water, and the calculated amount of coal particles were then added to the solution. 

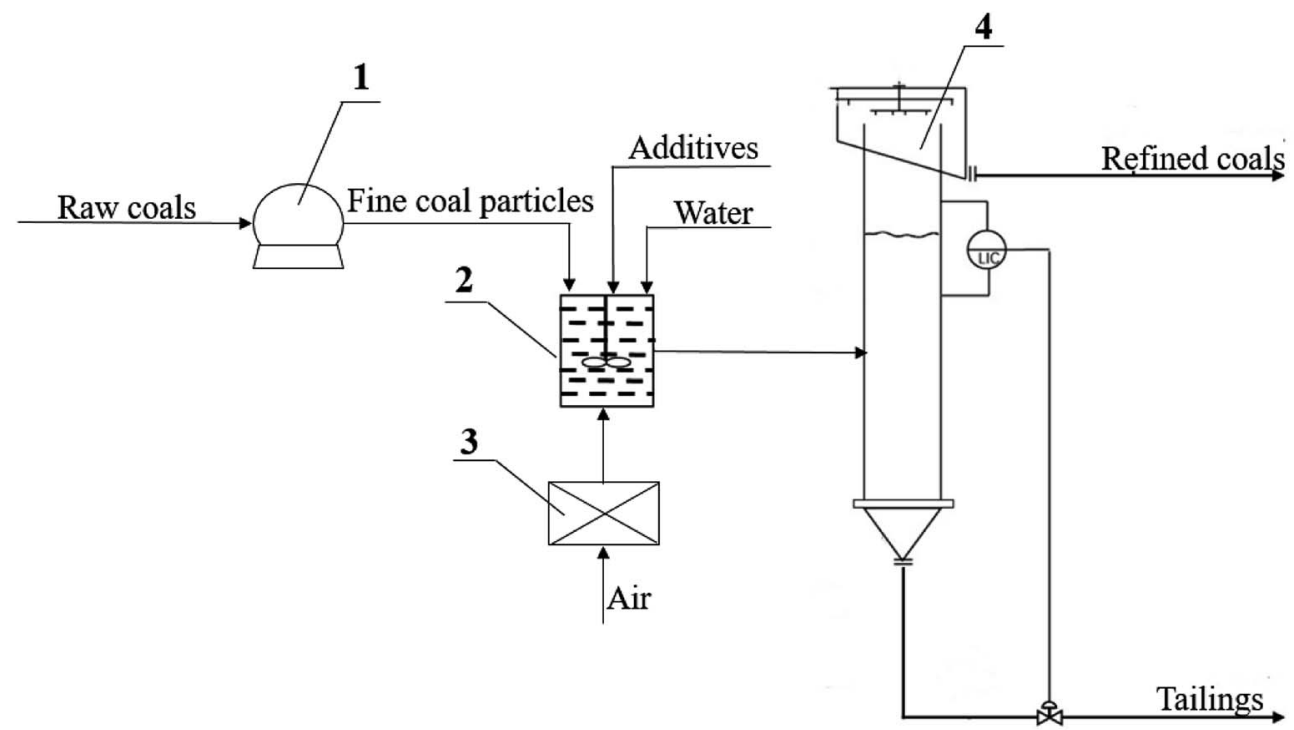

Fig. 1 The flow chart of pilot platform for refined coal production.

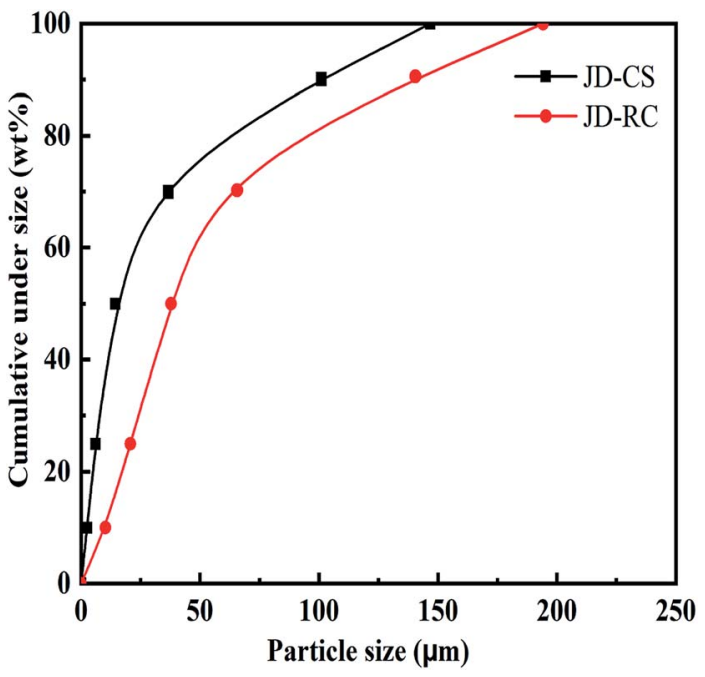

Fig. 2 Particle-size distribution of JD-CS and JD-RC used for slurry preparation.

The three dispersants including NSF, PPA and SMF were applied for CWS preparation, respectively. Descriptions of these additives were presented in Table 2. Solids loading of CWS in this study was calculated and discussed on moisture-free basis.
The mixture was stirred by a high-speed dispersing agitator for $5 \mathrm{~min}$ at $11200 \mathrm{rpm}$ to ensure the homogenization of CWS.

\subsection{Characterization and measurement}

2.3.1. Scanning electron microscope (SEM) and mineral liberation analyzer (MLA). Sample preparation steps for SEM measurement were described as follows: firstly, $0.1 \mathrm{~g}$ dry coal powder was dispersed in $10 \mathrm{~mL}$ ethanol solvent and then the suspension was sonicated for $30 \mathrm{~min}$; secondly, one drop of the suspension was deposited on the lofting platform of SEM and the ethanol on the platform would be evaporated gradually at room temperature; at last the sample was put into the electron microscope for detection.

The mineral maceral associations in coal only could be liberated by an ultrafine grinding equipment, and the MLA map highlighted the degree of grinding that would achieve significant additional liberation at the lowest energy consumption. Distribution of minerals in JD-CS were investigated by MLA 650 (FEI, USA), with an accelerating voltage of $20 \mathrm{~V}$ and a beam current of $5.1 \mathrm{nA}$. The magnification times of sample was $2000 \times$.

2.3.2 Infrared spectrum analyses. The Fourier transform infrared spectrometry of Nicolet iS10 by ThermoFisher was used for infrared spectrum analysis. $1 \mathrm{mg}$ of coal particles was mixed with $100 \mathrm{mg}$ of $\mathrm{KBr}$ in an agate mortar, which was thoroughly

Table 1 Proximate, ultimate and calorific value analyses of JD-CS and JD-RC ${ }^{a}$

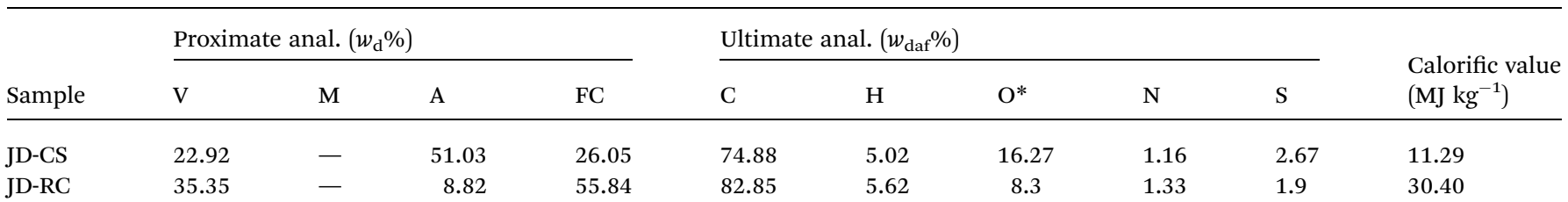

${ }^{a}$ Note: d, dry basis; daf, dry ash-free basis; *, by difference. 
Table 2 Additives used for this study

\begin{tabular}{lll}
\hline Abbreviations & Chemical composition & Manufacturer \\
\hline NSF & $\begin{array}{l}\text { Napthalene Sulfonate Formaldehyde } \\
\text { condensate }\end{array}$ & Wanshan Chemical Co. in China \\
PPA & $\begin{array}{l}\text { Polyoxyethylene Polycarboxylic Acid ether } \\
\text { Sulfonated Melamine-Formaldehyde resin }\end{array}$ & Lusen Chemical Co. in China \\
SMF & BASF in Germany & Anionic
\end{tabular}

cleaned by ethanol. The powder of the coal and $\mathrm{KBr}$ were pressed using tablet machine for $15 \mathrm{~min}$ with a pressure of $20 \mathrm{MPa}$. The FT-IR was calibrated with a pure KBr sample firstly, and then the experimental sample scans were conducted. FT-IR spectra of different coal particles were recorded in the range of $4000-400 \mathrm{~cm}^{-1}$.

2.3.3 Viscosity and rheological behavior. The apparent viscosity and rheological property of CWS were measured by the rotational rheometer (HAAKE MARS III by ThermoFisher Co., Germany), the slurries were transferred directly into the measuring fixtures. In order to obtain the flow curves and viscosity information of CWS, the shear rate was increased from 0 to $100 \mathrm{~s}^{-1}$ in $2 \mathrm{~min}$, and then held for $1 \mathrm{~min}$ at $100 \mathrm{~s}^{-1}$, finally returned back to $0 \mathrm{~s}^{-1}$ in another $2 \mathrm{~min}$. The average value of viscosity at $100 \mathrm{~s}^{-1}$ was used as the apparent viscosity of CWS. The accuracy of this measuring device is $0.01 \mathrm{mPa}$.

2.3.4 Contact angle measurement. Contact angle measurement was used for evaluating the wettability of coal surface, which was related to the surface free energy of the system. In this study, the results were measured using contact angle meter (DSA25S by KRUSS Co., German) and the accuracy of this experimental instrument is $0.1^{\circ}$. The coal particles were dried under vacuum at $105{ }^{\circ} \mathrm{C}$ for $12 \mathrm{~h}$, and then they were pelletized with a pressure of $30 \mathrm{MPa}$ for $20 \mathrm{~min}$. Afterwards, coal pellets with a diameter of $14 \mathrm{~mm}$ and a thickness of $2 \mathrm{~mm}$ could be obtained, and the contact angles of solution with different dosage and types of dispersants on coal surface were measured using the sessile drop technique. It indicated the changes in surface hydrophobicity of coal particles modified by different additives. Each experiment was tested for 5 times and the average value was used for comparison.

2.3.5 Surface tension measurement. The surface tension of different dispersants solution was measured on the surface tension apparatus (K100 by KRUSS Co., German) by a platinum loop. First, a calculated quantity of PPA was dissolved in deionized water to prepare the solutions with different PPA concentration i.e., 0/0.3/0.6/0.9/1.2/1.5 $\mathrm{g} \mathrm{L}^{-1}$, respectively. Then the solution with same concentration $\left(0.9 \mathrm{~g} \mathrm{~L}^{-1}\right)$ was produced by different dispersant including NSF, PPA, SMF severally. Each measurement was performed for surface tension measurement in 6 times at $25^{\circ} \mathrm{C}$. The precision of the surface tension meter was $0.01 \mathrm{mN} \mathrm{m}^{-1}$.

2.3.6 Zeta potential. The zeta potential of JD-RC with different dispersant was measured by ZetaPALS analyzer (Brookhaven, USA). Dilute CWSs ( $0.4 \mathrm{~g}$ pulverized coal in $200 \mathrm{~mL}$ deionized water with $0.6 \mathrm{wt} \%$ dispersant, accounted for the mass of dry-based coal) were mixed by a high-speed shearing dispersant machine (11200 rpm for $5 \mathrm{~min}$ ). The suspension was placed for $12 \mathrm{~h}$ under $25^{\circ} \mathrm{C}$, then the upper suspending liquid was used for potential measurement. For each case, five measurements were made and the mean value of the zeta potentials was utilized in this study.

\section{Results and discussion}

\subsection{SEM and MLA analysis of coal particle}

A fundamental understanding of the surface properties of coal particles was required in order to predict the rheological properties of slurries accurately. The morphological features of JDCS and JS-RC were compared at magnification multiples of $1000 \times$ and $4000 \times$ by SEM.

As shown in Fig. 3, the JD-CS had a rough surface with abundant pores, the surface of JD-RC was relatively smooth and the number of micro-pores was significantly decreased. The main reason might be the higher ash content in JD-CS and modification of collector in JD-RC. ${ }^{28}$ The improved SFF methods was an effective surface modification technology for fine particle treatment. In this work, due to the lower ash content and scarce pores in JD-RC, they were more suitable for the preparation of high concentration CWS than JD-CS. The ratio of free water and bound water around particles determined the fluidity of slurry. ${ }^{29}$ The bound water, which had little contribution to the fluidity of CWS, might account for a higher proportion in slurry prepared by JD-CS because of the higher mineral content and rich pores. ${ }^{30}$ As a result, JD-CS could hardly be used for preparing a qualified CWS in basic fluidity.

Associated information of primary JD-CS components were shown by MLA-derived map in Fig. 4. The mineral composition of JD-CS mainly included kaolinite, pyrite quartz and calcite. The kaolinite and quartz, which accounted for $57.51 \mathrm{wt} \%$ and $11.54 \mathrm{wt} \%$ of total mineral content in coal slime severally, displayed clump shaped disseminations obviously with particle size below $50 \mu \mathrm{m}$. However, the pyrite and calcite exhibited relatively fine size distribution, nearly $1-30 \mu \mathrm{m}$. The proportions of pyrite and calcite were $17.89 \mathrm{wt} \%$ and $3.99 \mathrm{wt} \%$, respectively. Due to high content, fine-grained distribution, strong hydrophily of those minerals in JD-CS, the ratio of bound water around particles might increases, and it was obviously disadvantageous for slurry preparation.

\subsection{Functional group of coal surface}

In the infrared spectrum, the characteristic peaks at 3695, 3619 and $913 \mathrm{~cm}^{-1}$ correspond to $\mathrm{O}-\mathrm{H}$ bond in kaolinite, but the spectrum peaks at 797 and $695 \mathrm{~cm}^{-1}$ were assigned to $\mathrm{Si}-\mathrm{O}$ 

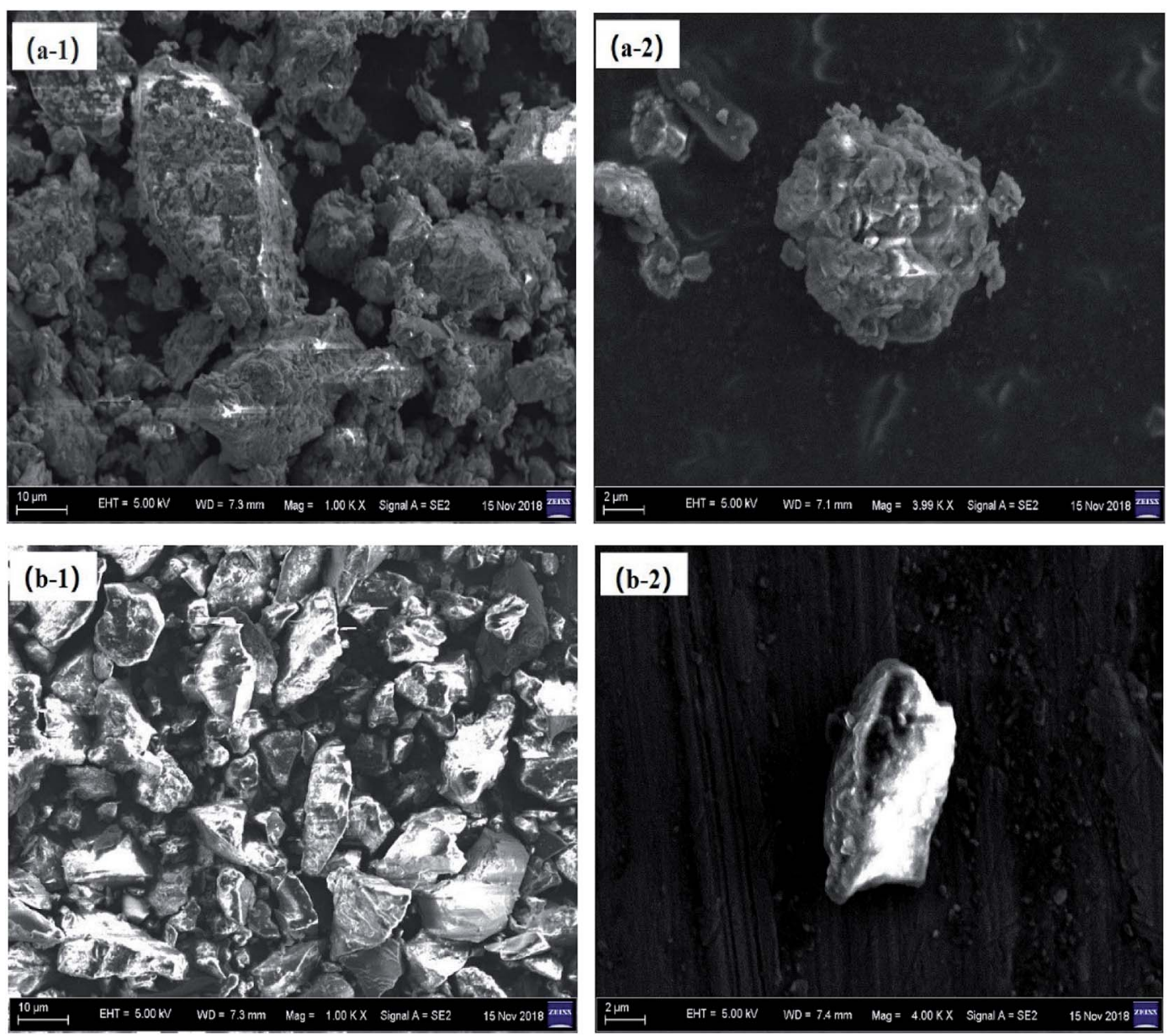

Fig. 3 SEM images of coal particles: (a) JD-CS, (b) JD-RC and (1) at $1000 \times$ scale, (2) at 4000× scale.

stretching vibration in quartz. For organic functional groups, the band at $2360 \mathrm{~cm}^{-1}$ and $1600 \mathrm{~cm}^{-1}$ suggested aromatic $\mathrm{C}-\mathrm{H}$ bond and aromatic $\mathrm{C}-\mathrm{C}$ on-ring stretch respectively.
It could be seen from the Fig. 5 that the types of functional groups on the surface of JD-CS and JD-RC were very similar. However, the peak strengths were quite different. Firstly, the peaks around 3619,3695 and $913 \mathrm{~cm}^{-1}$, which were assigned to

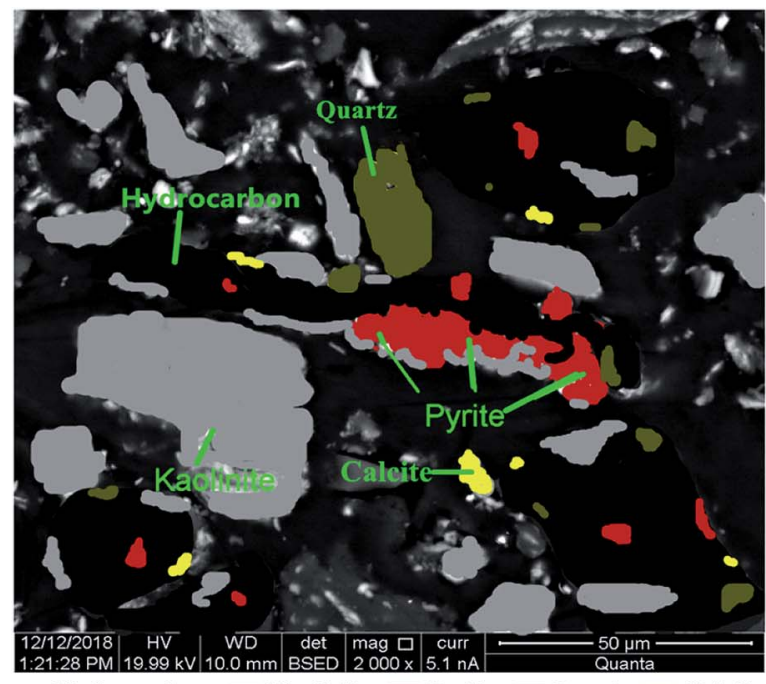

\begin{tabular}{|c|c|}
\hline \multicolumn{2}{|c|}{ Mineral components and relative content } \\
\hline Components & Content (\%) \\
\hline Kaolinite & 57.51 \\
\hline Pyrite & 17.89 \\
\hline Quartz & 11.54 \\
\hline Calcite & 3.99 \\
\hline Others & 9.07 \\
\hline Total & 100.00 \\
\hline
\end{tabular}

Fig. 4 The MLA image and mineral components of JD-CS. 


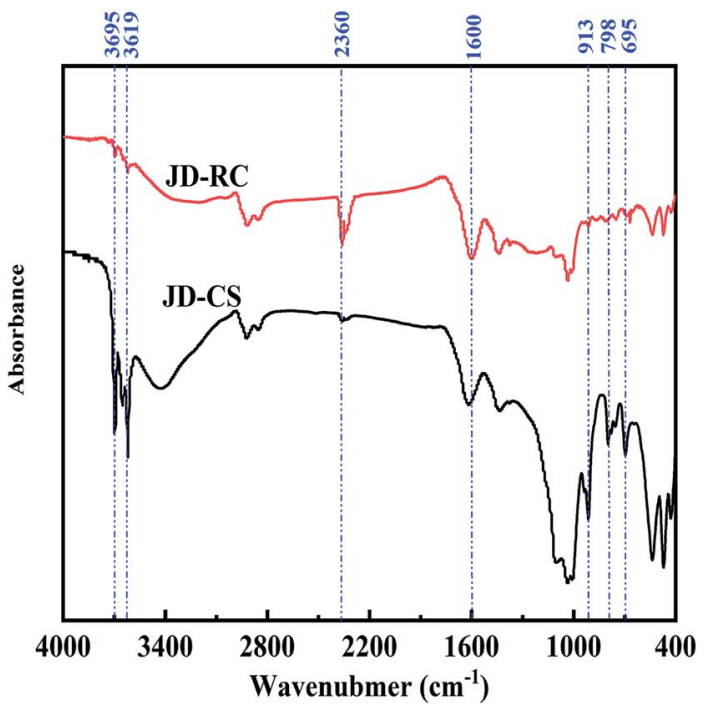

Fig. 5 FTIR spectroscopic analyses of coal particles.

hydrogen bond-associated $\mathrm{O}-\mathrm{H}$ stretching groups for kaolinite, were more pronounced in JD-CS; meanwhile, the two peak signals of 798 and $695 \mathrm{~cm}^{-1}$ in JD-CS were obviously stronger than that in JD-RC. Secondly, at $2360 \mathrm{~cm}^{-1}$ corresponding to $\mathrm{C}-\mathrm{H}$ groups (aromatic rings) and $1600 \mathrm{~cm}^{-1}$ corresponding to $\mathrm{C}=\mathrm{C}$ stretch (in-ring) aromatics, these two peaks were more prominent in JD-RC. The progressive loss of oxygen functional groups in JD-RC could promote the release of bound water and improve the fluidity of CWS. ${ }^{31}$

\subsection{Influence of solid concentration on apparent viscosity}

The maximum solid content of slurry was the coal concentration of CWS with the apparent viscosity around $1000 \mathrm{mPa} s$ at a shear rate of $100 \mathrm{~s}^{-1}$ in this study. The effect of solid content on CWS apparent viscosity was measured using JD-CS and JD$\mathrm{RC}$, respectively. As shown in Fig. 6, the apparent viscosity

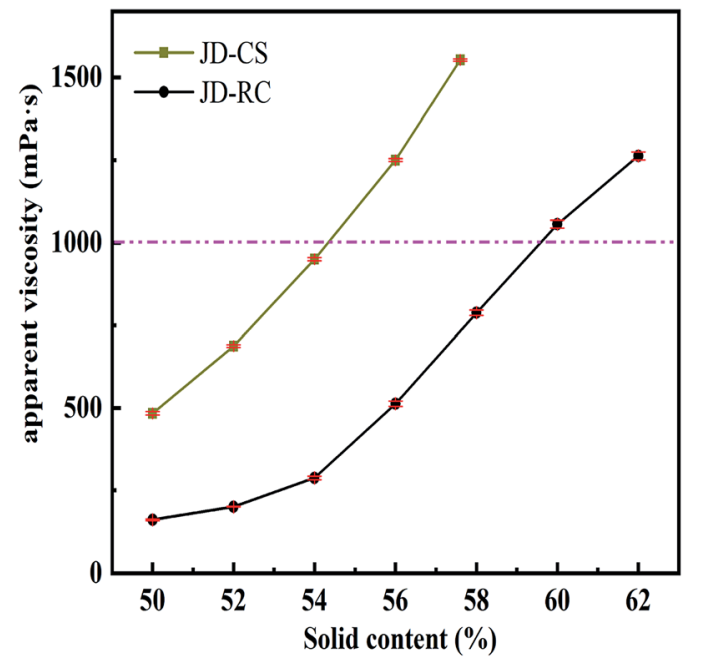

Fig. 6 The apparent viscosity of CWS with different solid content. values of CWS increased significantly with the increment of solid content. The increasing of the suspension viscosity as a function of coal quantity could be related to the particle interactions. ${ }^{32}$ The free volume among coal particles was larger and agglomeration was rare at relatively low slurry concentration, resulting in a lower apparent viscosity. With the sustained addition of coal loading, the free volume became smaller and contact probability among coal particles increased.

It could be seen from Fig. 6, when the solid content of CWS prepared by JD-CS increased from $50 \%$ to $54 \%$, the apparent viscosity of CWS (without any dispersants) varied from 428.16 $\mathrm{mPa} s$ to $948.35 \mathrm{mPa} \mathrm{s}$ at the shear rate of $100 \mathrm{~s}^{-1}$, and the apparent viscosity increased sharply with further addition of JDCS. However, the apparent viscosity of CWS prepared by JD-RC increased from 160.29 to $1045.75 \mathrm{mPa} s$ as a function of solid content with a range from 50 to $60 \mathrm{wt} \%$. The maximum solid concentration of slurry increased from 54 to $60 \mathrm{wt} \%$ after the low quality coal had been upgraded by improved SFF method, the main reason might be the decrement of mineral and hydrophilic functional groups in coal particles after flotation. As shown in Fig. 4 and 5, kaolinite, which significantly increases the apparent viscosity of slurry, ${ }^{33}$ was the most abundant mineral group in primary JD-CS.

\subsection{Apparent viscosity of $60 \mathrm{wt} \%$ CWS with different dispersant}

The variation of apparent viscosity for CWS with different concentration of NSF, PPA, and SMF through loading $60 \mathrm{wt} \%$ coal at shear rate of $100 \mathrm{~s}^{-1}$ was demonstrated in Fig. 7. With the increasing of dispersant dosage, the apparent viscosity of every slurry sample decreased in total, but the decrement of viscosity value became slower after the dosage of dispersant exceeded $0.6 \mathrm{wt} \%$ for all CWS samples. As can be seen from Fig. 7, the apparent viscosity of CWS without any dispersant was $1045.75 \mathrm{mPa} \mathrm{s}$. When the addition of dispersant reached $0.6 \mathrm{wt} \%$ and $1.0 \mathrm{wt} \%$, the viscosity of CWS prepared by NSF

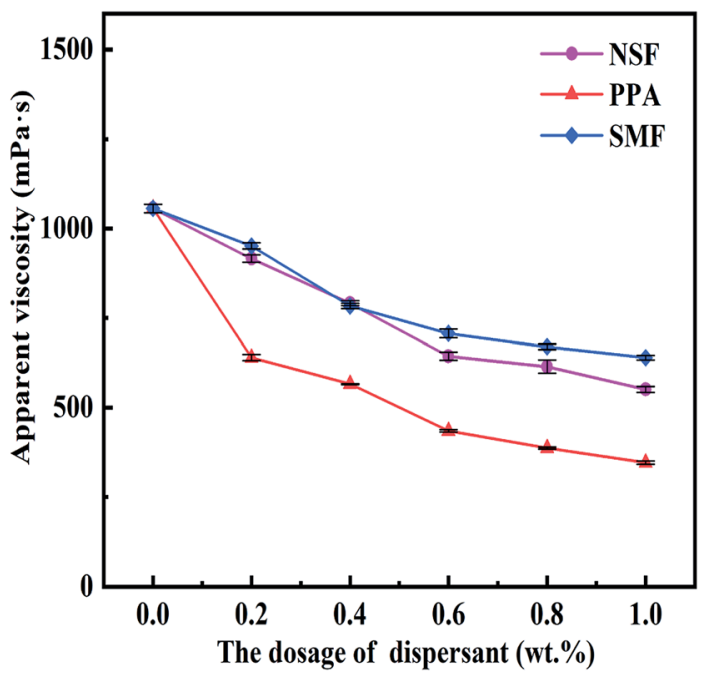

Fig. 7 Apparent viscosity of CWS at different dosages of NSF, PPA and SMF (60 wt\%, at a shear rate of $\left.100 \mathrm{~s}^{-1}\right)$. 
decreased to $640.77 \mathrm{mPa}$ s and $552.08 \mathrm{mPa}$ s respectively, but the viscosity with PPA dropped to $435.93 \mathrm{mPa} \mathrm{s}$ and 344.96 $\mathrm{mPa} \mathrm{s}$, while the viscosity for SMF lowered to $698.62 \mathrm{mPa}$ s and $649.27 \mathrm{mPa}$. The viscosity reduction ability for $60 \mathrm{wt} \% \mathrm{CWS}$ was really discrepant with different dispersants. Among these three dispersants, the viscosity value of CWS prepared by PPA dispersant was always the lowest at the same dosage of dispersant. The results illustrated that PPA dispersant was more suitable for CWS preparation by JD-RC than NSF and SMF dispersant.

It was demonstrated that the dispersing ability of dispersant was influenced by the side-chain structure. ${ }^{34}$ First of all, the dispersant accompanied by a long side chain could provide steric protection to reduce the agglomeration of coal particles and lower the apparent viscosity of CWS. ${ }^{34,35}$ Furthermore, the hydrophilicity of coal particles was greatly enhanced because carboxyl groups of PPA dispersant, ${ }^{36}$ which was beneficial to improve the dispersibility of coal particles in solution. Hence, the PPA dispersant had a better dispersing and viscosityreducing effect on CWS prepared by JD-RC.

\subsection{Rheological behavior of CWS with different dispersants}

The CWS application was influenced by the rheological properties dramatically. An ideal liquid-phase fuel should be prepared with low apparent viscosity and good flow pattern. ${ }^{37,38}$ The rheogram of CWS between apparent viscosity and shear stress as a function of shear rate by using different dispersant with coal content of $60 \mathrm{wt} \%$ could be seen in Fig. 8(a) and (b). In order to gain better viscosity-reducing effects, the dosage of each dispersant was $0.6 \mathrm{wt} \%$ on the dried coal basis. The blank curve means $60 \mathrm{wt} \%$ CWS without any dispersant.

The flow pattern of CWS with different dispersant exhibited a shear thinning fluid behavior with a yield stress, and it could be described by rheological parameters in the relevant equation. In this study, the relationship between the apparent viscosity and shear rate was found in line with Herschel-Bulkley fluids ${ }^{39}$ obeying eqn (1):
Table 3 Rheological parameters calculated by Herschel-Bulkley model

\begin{tabular}{llllll}
\hline Dispersants & $\begin{array}{l}\text { Apparent viscosity } \\
(\mathrm{mPa} \mathrm{s})\end{array}$ & $\tau_{0}(\mathrm{~Pa})$ & $\begin{array}{l}K \\
\left(\mathrm{~Pa} \mathrm{~s}^{n}\right)\end{array}$ & $n$ & $R^{2}$ \\
\hline Blank & 1045.75 & 43.67 & 0.99 & 0.91 & 0.9999 \\
NSF & 640.77 & 24.82 & 0.39 & 1 & 1 \\
PPA & 435.93 & 3.93 & 1.46 & 0.72 & 0.9992 \\
SMF & 697.91 & 44.53 & 0.02 & 1.63 & 0.9994 \\
\hline
\end{tabular}

$$
\tau=\tau_{0}+K \gamma^{n}
$$

where $\tau_{0}, K$ and $n$ denote the yield stress, the fluid consistency coefficient and the flow behavior index, respectively. The values of the calculated Herschel-Bulkley parameters were given in Table 3 .

The apparent viscosity versus shear rate curves of CWS with different dispersants were shown in Fig. 8(a). It could be seen that the apparent viscosities of CWS decreased with the increment of shear rate (shear thinning) gradually due to the gradual breakup of shear aggregates. ${ }^{40}$ Therefore, the CWS prepared by those three types of dispersants belonged to shear-thinning fluids. As can be seen in Fig. 8(a), for CWS without any dispersant, the viscosity was the largest among all the samples at the same shear rate. By contrast, the apparent viscosity of CWS with PPA dispersant was the lowest among those three additives. It was demonstrated that PPA, as an effective dispersant for CWS preparation, had a better viscosity-reducing ability than NSF and SMF dispersant.

It could be seen from Fig. 8(b) that the shear stress value increased with the increment of shear rate for each CWS. At the same shear rate, the order of shear stress value of CWS with different dispersant were as following: PPA $<\mathrm{NSF}<\mathrm{SMF}<$ Blank, and the trend was consistent with the apparent viscosity regular in Fig. 8(a). It was well known that CWS yield stress should be as low as possible to obtain better dispersion, which
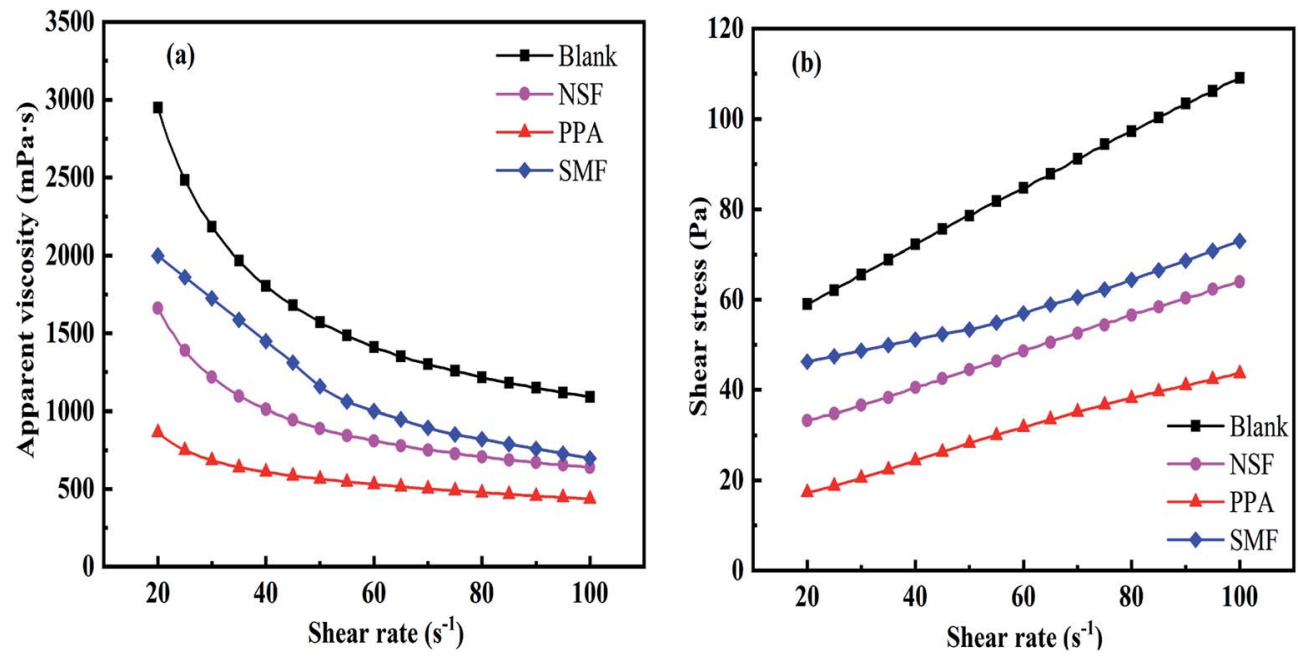

Fig. 8 Rheological behavior of CWS with different dispersants: (a) for apparent viscosity and (b) for shear stress. 
meant that initial stress should be more easily overcome to make CWS liquid flow and transport. ${ }^{\mathbf{4 1}}$ To define the value of yield stress, the higher shear rate of each rheogram was extrapolated to shear rate of $0 \mathrm{~s}^{-1}$.

As shown in Table 3, as all of the fitting constants $R^{2}$ were around 1, the rheological behavior of CWS could be well described by eqn (1). However, the values of the flow behavior index $(n)$ and the fluid consistency coefficient $(K)$ were quite different for CWS with different dispersants. The values of flow behavior index $(n)$ for CWS with PPA was less than 1, which indicated that the slurries come out to be pseudoplastic fluid. From Table 3, the CWS with PPA dispersant exhibited excellent fluidity because of the lowest yield stress (3.93 Pa), which was consistent with the result of lowest apparent viscosity (435.93 $\mathrm{mPa} s$ at the shear rate of $100 \mathrm{~s}^{-1}$ ). The CWS prepared with NSF dispersant was the bingham plastic fluid because the values of flow behavior index $(n)$ was 1 , and the yield stress of CWS with NSF was $24.82 \mathrm{~Pa}$. However, the value of flow characteristic index $(n)$ for CWS with SMF dispersant was greater than 1, indicating that the slurry belonged to expansive plastic fluids. The yield stress of CWS with SMF was 44.53 Pa. From Table 3, the yield stress of CWS with NSF and SMF dispersant was higher than that of CWS with PPA dispersant. It might be explained that the anionic surfactant, which could be adsorbed on coal surface, would increase the electrostatic repulsion force between coal particles. It could be seen from the results in the Table 3 that PPA dispersant was the optimal dispersant for CWS preparation, due to the lowest apparent viscosity (435.93 $\mathrm{mPa} \mathrm{s}$ ) and yield stress (3.93 Pa).

\subsection{Wettability of different dispersants on coal surface}

The contact angle reflected the macroscopic average wettability of coal surface. ${ }^{\mathbf{4 2}}$ In order to compare the hydrophobicity/ hydrophilicity of the coal particle with different dispersant, the contact angles were tested on the coal surfaces modified by different dispersant with the dosage of $0.6 \mathrm{wt} \%$.

As shown in Fig. 9, the contact angle of JD-RC particles in water was $58.1^{\circ}$, and it decreased after the dispersant was adsorbed on coal particles. The corresponding contact angle of NSF, PPA and SMF dispersant was decreased to $44.3^{\circ}, 37.9^{\circ}$ and $52.6^{\circ}$ respectively. An increase in hydrophilicity reduced the network formation tendencies of slurry, which minimized the trapping of free water, and more free water was available for the fluidity of slurry. The addition of dispersant increased its hydrophobicity and therefore aided in viscosity reduction. The contact angles of PPA dispersant on coal surface were the lowest among these three dispersants, which demonstrated that PPA dispersant induced a sharp decrease in hydrophobicity of coal particle surface and prevent coal particles from aggregation. The main reason was that PPA possessed a large number of carboxyl groups, and these structure characteristics made it easier to become a hydrophilic surface on coal particles, which was favorable to the wettability of coal particles. In addition, PPA molecules contained a mass of polyoxyethylene branches to form large and stable adsorbed layers on the coal particle surface, which could offer the steric hindrance to disperse the

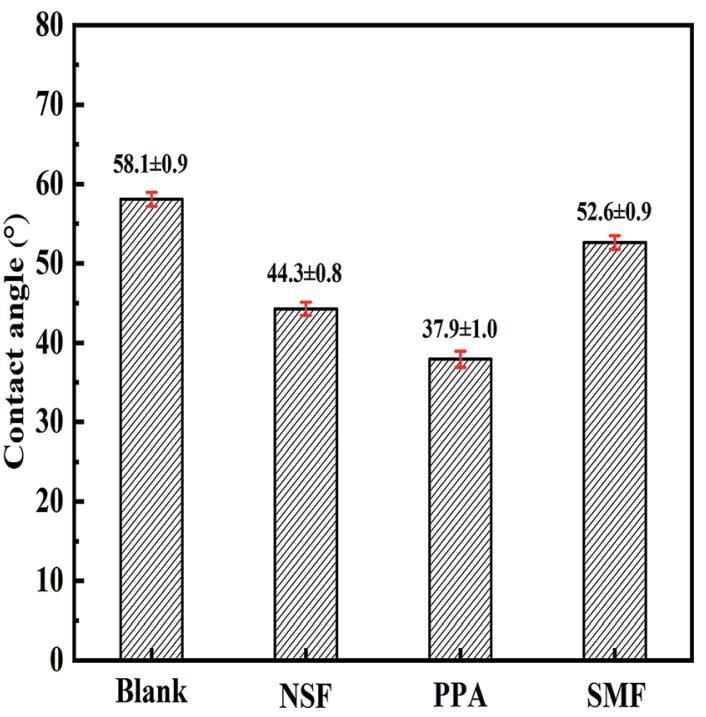

Fig. 9 Contact angle on the coal surfaces with different dispersants.

coal particles better. Therefore, with the modification by PPA on coal surface, the initial strong attractive interaction energy of coal particles was considerably reduced, resulting in an uniformly dispersed system. ${ }^{43}$ Thus, PPA dispersant was the most effective surfactant in the case of refined CWS preparation.

\subsection{Influence of dispersants on surface tension of deionized water}

The surface tension of the solution with different PPA concentrations were measured to characterize the variable-strength of deionized water. The relationship between the surface tension and PPA dosage was given in Fig. 10. Here, the mass ratio of PPA dispersant and water was consistent with the PPA dosage of CWS in Section 3.4. Fig. 10 showed that the surface tension of

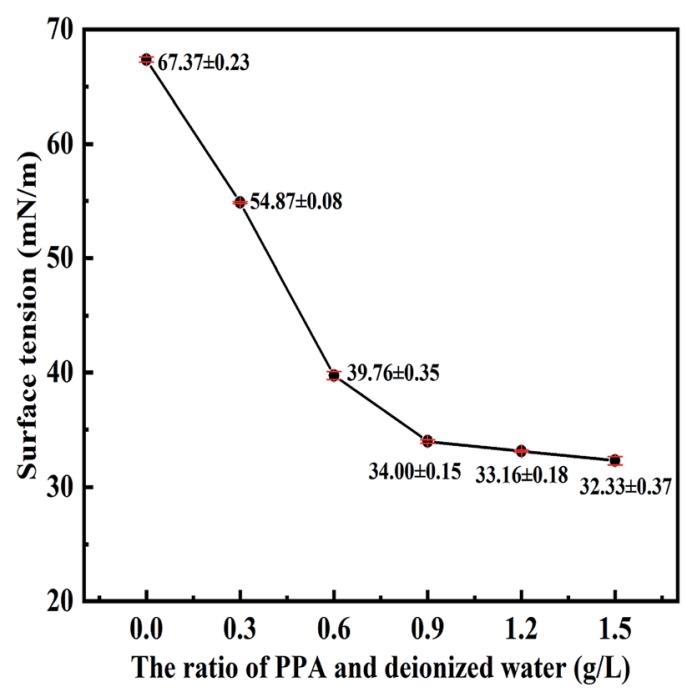

Fig. 10 The surface tension of deionized water as a function of PPA concentration. 
solution was influenced by PPA concentrations significantly. The surface tension of PPA solution decreased dramatically when the dispersant concentration increased from 0 to $0.9 \mathrm{~g}$ $\mathrm{L}^{-1}$, with the value of surface tension varied from $67.37 \mathrm{mN} \mathrm{m}^{-1}$ to $34 \mathrm{mN} \mathrm{m}^{-1}$. And then the value almost kept constant when the concentration was more than $0.9 \mathrm{~g} \mathrm{~L}^{-1}$. Therefore, the critical micellar concentration of PPA dispersant was $0.9 \mathrm{~g} \mathrm{~L}^{-1}$, which was consistent with the viscosity-reducing effect of CWS with PPA dosage in Section 3.4.

As previously stated in literature, ${ }^{44}$ dispersants spontaneously reduced the aggregating tendency of hydrophobic coal powder in suspensions by eliminating the interface force difference between coal particles and water. In other words, it could increase the surface force of coal particles and reduce the surface tension of deionized water. The critical concentration of PPA dispersant for reducing surface tension of deionized water was $0.9 \mathrm{~g} \mathrm{~L}^{-1}$. As a comparison, the surface tension of NSF and SMF solution with the concentration of $0.9 \mathrm{~g} \mathrm{~L}^{-1}$ was also described in Fig. 11. It can be seen that the surface tension of NSF and SMF solution were $58.56 \mathrm{mN} \mathrm{m}^{-1}$ and $62.24 \mathrm{mN} \mathrm{m}^{-1}$, respectively. Apparently, PPA dispersant had the most significant effect on reducing the surface tension of deionized water. This regular was consistent with the results of viscosity measurement for different dispersants in Section 3.4, which indicated that the PPA dispersant had the best viscosityreducing effects on CWS preparation.

\subsection{Zeta potential of coal particle with different dispersant}

Electrostatic interaction of coal particle in suspension were estimated by the value of zeta potential. ${ }^{45}$ NSF, PPA and SMF were used as dispersant for suspension preparation, respectively. As could be illustrated in Fig. 12 that the zeta potential of JD-RC without any dispersant addition was nearly $-25 \mathrm{mV}$, whereas the zeta potential reached a lower absolute value of approximately $-48 \mathrm{mV}$ when SMF dispersant was added into

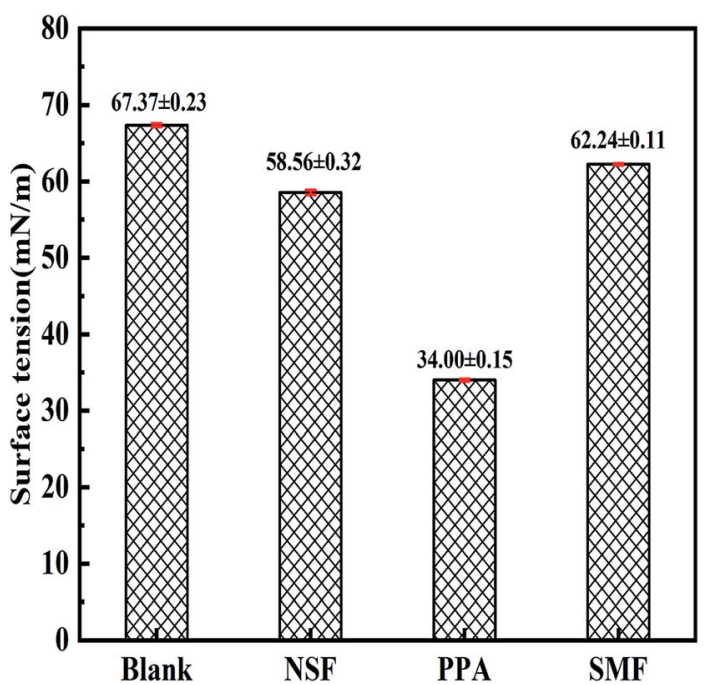

Fig. 11 The surface tension of deionized water with different dispersants.

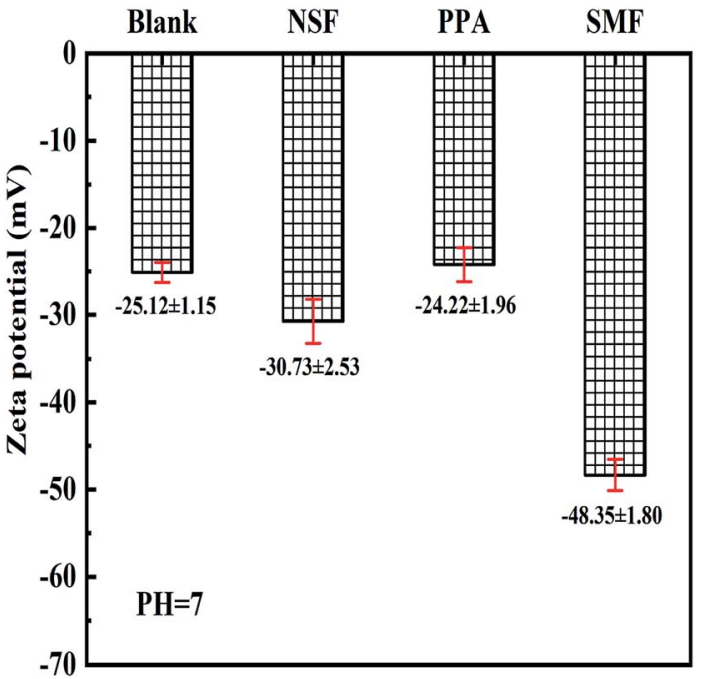

Fig. 12 Zeta potential of coal particle with different dispersant.

suspension and $-31 \mathrm{mV}$ if NSF dispersant was chosen for suspension preparation. However, in the presence of PPA dispersant, the value of zeta potential decreased to $-24 \mathrm{mV}$, which indicated that the electrostatic repulsion between particles could not be strengthened by PPA dispersant.

It was clear from Fig. 8 that PPA dispersant exhibited the optimum performance on lowering the apparent viscosity of CWS among these three additives. However, the negative charge of particle surface wasn't improved by PPA dispersant, which meant the PPA dispersant didn't enhance the electrostatic force between particles. Therefore, a considerable decrease in viscosity of CWS was mainly due to the wettability improvement of coal surface and the decrease in surface tension of deionized water.

\section{Conclusion}

In this study the effects of parameters such as the surface properties of coal particles before and after flotation treatment, the solid content of CWS, the dosage and types of dispersants on the rheological behaviors of CWS were investigated. The conclusions could be briefly drawn as follows:

(1) Through the improved SFF process, the pores and hydrophilic functional groups on coal surface were significantly reduced, which was beneficial for slurry preparation. When the apparent viscosity of CWS was $(1000 \pm 100) \mathrm{mPa}$ at a shear rate of $100 \mathrm{~s}^{-1}$, the highest solid content of slurry prepared by JD-CS was $54 \mathrm{wt} \%$, whereas the concentration of slurry prepared by JD$\mathrm{RC}$ could reach $60 \mathrm{wt} \%$. The lower slurry concentration of JD-CS was resulted from the abundant pore structure and the rich content of kaolinite.

(2) It had been discovered that PPA dispersant had better viscosity-reducing effect and rheological property than NSF and SMF dispersant for CWS preparation. For CWS preparation by JD-RC in this study, a marked reduction on apparent viscosity of CWS by dispersant was mainly attributed to wettability improvement of particle surface and surface tension decrement 
of deionized water instead of changes in particle electronegativity.

The results in this research had manifested a good feasibility for qualified CWS preparation from coal slime, which was difficult to handle in industry. The comprehensive approach opened up a direct means on fully utilization of the low quality coal in response to energy and environmental challenges. Certainly, a more detailed study was required to further explore gasification and combustion performance of CWS prepared by refined coal derived from the low quality coal.

\section{Conflicts of interest}

There are no conflicts of interest to declare.

\section{Nomenclature}

$\begin{array}{ll}\text { CWS } & \text { Coal water slurry } \\ \text { NSF } & \text { Napthalene Sulfonate Formaldehyde condensate } \\ \text { PPA } & \text { Polyoxyethylene Polycarboxylic Acid ether } \\ \text { SMF } & \text { Sulfonated Melamine-Formaldehyde resin } \\ \text { SEM } & \text { Scanning electron microscope } \\ \text { FT-IR } & \text { Fourier transform infrared spectroscopy } \\ \text { SFF } & \text { Selective flocculation flotation } \\ \text { JD-RC } & \text { Jinda refined coal } \\ \text { JD-CS } & \text { Jinda coal slime } \\ \text { MLA } & \text { Mineral liberation analyzer } \\ \text { T } & \text { Shear stress } \\ \tau_{0} & \text { Yield stress } \\ K & \text { fluid consistency coefficient } \\ \gamma & \text { Shear rate } \\ n & \text { Flow behavior index }\end{array}$

\section{Acknowledgements}

The authors gratefully acknowledge the financial support by Guangdong Innovative and Entrepreneurial Research Team Program (No. 2016ZT06N532) with Shenzhen Government Related Supporting Fund (No. KYTDPT20181011104002), Shenzhen Clean Energy Research Institute Project (No. CERIKY-2019-003), Development and Reform Commission of Shenzhen Municipality and Shenzhen High-Level Professional Program (No. 20160802681J).

\section{References}

1 M. A. Dmitrienko, G. S. Nyashina and P. A. Strizhak, J. Hazard. Mater., 2017, 338, 148-159.

2 Y. Shen, X. Liu, T. Sun and J. Jia, RSC Adv., 2012, 2, 88678882.

3 G. S. Nyashina, G. V. Kuznetsov and P. A. Strizhak, J. Cleaner Prod., 2018, 172, 1730-1738.

4 G. Atesok, F. Boylu, A. A. Sirkeci and H. Dincer, Fuel, 2002, 81, 1855-1858.

5 J. Cheng, X. Wang, F. Zhou, R. Huang, A. Wang, X. Chen, J. Liu and K. Cen, RSC Adv., 2015, 5, 14690-14696.
6 H. Lu, X. Guo, P. Li, K. Liu and X. Gong, Chem. Eng. Res. Des., 2017, 120, 208-217.

7 Y. C. Wei, B. Q. Li, W. Li and H. K. Chen, Coal Prep., 2005, 25, 239-249.

8 D. Lv, W. Yuchi, Z. Bai, J. Bai, L. Kong, Z. Guo, J. Yan and W. Li, Fuel, 2015, 145, 143-150.

9 R. Yavuz and S. Kucukbayrak, Powder Technol., 2001, 119, 8994.

10 Y. Ding and Y. Li, J. Fuel Chem. Technol., 2005, 33, 661-665.

11 G. Zhang, N. Zhu and X. Zhu, J. Dispersion Sci. Technol., 2016, 37, 1799-1805.

12 K. Zhang, Y. Li, Z. Wang, Q. Li, R. Whiddon, Y. He and K. Cen, Fuel, 2016, 185, 701-708.

13 M. Li, S. F. Bao and L. F. Qiu, in Material Sciences and Technology, Pts 1 \& 2, ed. Y. Li, 2012, vol. 560-561, pp. 627-631.

14 Z. Aktas and E. T. Woodburn, Fuel Process. Technol., 2000, 62, 1-15.

15 G. Cai, M. Ma, Y. Xiong, C. Zhang and W. Guo, Chem. Ind. Eng. Prog., 2014, 33, 70-74.

16 D. Jambal, B.-G. Kim, H.-S. Jeon and J.-H. Lee, Sep. Sci. Technol., 2017, 52, 958-964.

17 G. Wang, X. Bai, C. Wu, W. Li, K. Liu and A. Kiani, Fuel Process. Technol., 2018, 178, 104-125.

18 H. Wang, J. Min. Sci., 2003, 39, 410-414.

19 W. Zou, Y. Cao, C. Sun and Z. Zhang, Chinese Journal of Engineering, 2016, 38, 299-305.

20 N. I. Nikitin, Coke Chem., 2008, 51, 171-173.

21 N. Hong, Y. Li, W. Zeng, M. Zhang, X. Peng and X. Qiu, RSC Adv., 2015, 5, 21588-21595.

22 R. Xu, W. Zhuang, Q. He, J. Cai, B. Hu and J. Shen, AIChE J., 2009, 55, 2461-2467.

23 G. Zhang, J. Li, J. Zhu, Q. Qu and W. Xiong, Powder Technol., 2014, 254, 572-578.

24 J. Huang, J. Xu, D. Wang, L. Li and X. H. Guo, Ind. Eng. Chem. Res., 2013, 52, 8427-8435.

25 G. Zhang, F. Zhao and J. Li, in Frontiers of Materials, Chemical and Metallurgical Technologies, Pts 1 and 2, ed. J. C. M. Kao, W. P. Sung and R. Chen, 2012, vol. 581-582, pp. 330-333.

26 Z. Li, Y. H. Fu, C. Yang, W. Yu, L. J. Liu, J. Z. Qu and W. Zhao, Miner. Eng., 2018, 126, 74-81.

27 D. Liu, Z. Wang, X. Chen and M. Liu, Powder Technol., 2018, 336, 102-111.

28 W. Xia, Y. Li and A. V. Nguyen, J. Cleaner Prod., 2018, 195, 1183-1189.

29 H. Y. Huai, M. Odlyha and A. Gaines, Fuel, 1994, 73, 465-469. 30 J. Zhang, H. Zhao, C. Wang, W. Li, J. Xu and H. Liu, Fuel, 2016, 177, 19-27.

31 Y. Zhang, G. Wu, X. Meng, Z. Yun, F. Shi, Y. He and X. Luo, Min. Sci. Technol., 2011, 21, 767-771.

32 T. F. Tadros, Colloids Surf., 1986, 18, 137-173.

33 P.-I. Au and Y.-K. Leong, Colloids Surf., A, 2013, 436, 530-541. 34 J. Zhu, G. Zhang, G. Liu, Q. Qu and Y. Li, Fuel Process. Technol., 2014, 118, 187-191.

35 G. H. Zhang, N. Zhu, Y. B. Li, J. F. Zhu, Y. R. Jia and L. Ge, Fuel Process. Technol., 2017, 161, 1-7. 
36 Z. Y. Yang, Z. Y. Meng, Z. H. Li and S. T. Wang, Mater. Sci. Forum, 2017, 896, 167-174.

37 N. S. Roh, D. H. Shin, D. C. Kim and J. D. Kim, Fuel, 1995, 74, 1220-1225.

38 J. Zhang, H. Zhao, W. F. Li, M. H. Xu and H. F. Liu, Sci. Rep., 2015, 5, 8.

39 G. R. Burgos, A. N. Alexandrou and V. Entov, J. Rheol., 1999, 43, 463-483.

40 P. Phulkerd, N. Thongchul, K. Bunyakiat and A. Petsom, Fuel Process. Technol., 2014, 119, 256-262.
41 A. Bartosik, J. Theor. Appl. Mech., 2011, 49, 283-300.

42 G. Zhou, C. Xu, W. Cheng, Q. Zhang and W. Nie, J. Anal. Methods Chem., 2015, 2015, 1-8.

43 J. E. Hirsch, Phys. Rev. Lett., 1985, 54, 1317-1320.

44 M. Ju, S. S. Ye, H. T. Low, J. F. Zhang, P. Cabrales, H. L. Leo and S. Kim, Phys. Biol., 2013, 10, 10.

$45 \mathrm{H}$. Bouhamed, S. Boufi and A. Magnin, J. Colloid Interface Sci., 2009, 333, 209-220. 